\title{
Fine Needle Aspiration Cytology in Cervical Lymphadenopathy; A Key to Divergent Locks.
}

\author{
Dr.Poonam Woike ${ }^{1}$, Dr.Ravi Bhagat ${ }^{2}$, Dr. Rajesh Gaur ${ }^{3}$, Dr. Dharmesh Chandra \\ Sharma $^{4}$ \\ ${ }^{1}$ Post Graduate Student, Department Of Pathology, G.R Medical College, Gwalior M.P, India. \\ ${ }^{2}$ Demonstrator, Department Of Pathology, G.R Medical College, Gwalior M.P, India. \\ ${ }^{3}$ Professor \& Head, Department Of Pathology, G.R Medical College, Gwalior, M.P, India. \\ ${ }^{4}$ ABTO, Incharge Blood Bank, J.A Hospital, Gwalior, M.P, India.
}

\begin{abstract}
Cervical lymphadenopathy is ranked among the most common clinical findings encountered in patients with multiple diseases ranging from benign to malignant lesions. Fine needle aspiration cytology (FNAC) is an effective tool for the assessment and diagnosis of superficial cervical lymph node enlargement. The aim of our study is to see the spectrum of lesions causing cervical lymphadenopathy in our region and the role of FNAC in its definite and early diagnosis. In these 6 years data of a total number of 1338 patients with cervical lymphadenopathy which were referred from the outpatient clinics for cytological examination were retrieved. FNAC was performed using 23 gauge needle attached to $20 \mathrm{ml}$ syringe. Aspirated materials were smeared into 2-3 slides which were stained with May Grunwald Giemsa (MGG) stain and using Dibutyl Phathalate Xylene (D.P.X) mountant, were prepared for cytological examination. Six year data was collected and compiled into various categories. Tubercular lymphadenitis $(53.8 \%)$ was the commonest cause of lymphadenopathy followed by reactive lymphoid hyperplasia (27.8\%), metastasis (14.6\%) and lymphomas (3.6\%). Squamous cell carcinoma (10.7\%) followed by adenocarcinoma (3.9\%) were the most frequent metastatic tumors. FNAC is a useful diagnostic tool and a valuable revolution in the management of patients presenting with cervical lymphadenopathy and should be considered before more invasive and costly procedures are performed, particularly in developing countries with resource poor settings.
\end{abstract}

Keywords: Lymphadenopathy, FNAC, Diagnosis, Malignancy, tubercular lymphadenitis.

\section{Introduction}

Enlarged lymph nodes were the first organs to be sampled by fine needle aspiration (FNA); today, they are one of the most frequently sampled tissues. The earliest report of a wider application of FNA came from USA in1921 when Guthrie described using aspirated material to diagnose a variety of diseases causing lymphadenopathy [1]. Lymphadenopathy refers to nodes that are abnormal in size, consistency or number (Darnal et al., 2005) [2]. It is a clinical manifestation of regional or systemic disease and serves as an excellent clue to the underlying disease. Lymph nodes are the easily accessible components of lymphoid tissue that not only clean and filter lymph but also produce lymphocytes and antibodies. The human body has approximately 600 lymph nodes, some of which such as submandibular, axillary or inguinal lymph nodes may normally be palpable in healthy people. Cervical lymphadenopathy is a fairly common clinical presentation. It is often a diagnostic challenge to medical professionals. A person with cervical Lymphadenopathy has swollen lymph glands in the neck. Lymph nodes most often swell in response to infection or inflammation. The present study try to give an idea to proceed with such cases and also try to give insight to the medical professional about the overall quantum of the problem, diagnostic outcome and role of newer diagnostic methods including the FNAC (Fine needle Aspiration cytology) among patients presenting with Cervical Lymphadenopathy. Cervical Lymphadenopathy can be presented as an isolated or as a part of generalized lymphadenopathy. Less commonly, lymph gland swelling can be a sign of cancer [2].

The various types are - reactive (due to acute or chronic infections), tumoral (Hodgkin and nonhodgkin lymphoma), autoimmune (SLE, rheumatoid arthritis) and malignancy (squamous cell and adenocarcinoma). FNAC is an easy, safe, reliable, rapid and inexpensive method for diagnosing enlarged lymph nodes with a high degree of accuracy. The physician's task is to efficiently differentiate the few patients with serious illness from the many with self-limited disease. This article reviews the evaluation of patients with a central clinical finding of lymphadenopathy, emphasizing the identification of patients with serious illness [3]. Fine needle aspiration cytology is a simple, quick and inexpensive method that is used to sample superficial masses like those found in the neck and is usually performed in the outpatient clinic. 
Fine Needle Aspiration Cytology in Cervical Lymphadenopathy; A Key to Divergent Locks.

Malignancies in lymph nodes in our country are predominantly metastatic in nature with an incidence varying from $65.7 \%$ [4] to $80.4 \%$ [5] and lymphomas range from $2 \%$ [6] to $15.3 \%$ [5] among lymph nodes aspirated from all sites, although, histopathological examination is considered to be gold standard in definitive diagnosis especially in lymphomas.

Among the inflammatory lesions tuberculosis (TB) is one of the most common infective causes of superficial lymphadenopathy in developing countries [7,8] including Nigeria.

We now have a large body of evidence supporting the use of FNA as a primary method of diagnosis in reactive, infective, tumoral and metastatic lymphadenopathy, but the diagnosis of malignant lymphoma by FNA has been much more controversial. However, recent studies have shown conclusively that a combined cytological and immunological evaluation of aspirated lymphoid cells results in distinctly improved diagnostic accuracy in cases of lymphoma. [9]

\section{Aims and objectives}

The aim of our study is to find out the prevalence of cervical lymphadenopathy in our region, to know the spectrum of lesions causing it and the role of FNAC in its early and effective diagnosis.

\section{Materials and methods}

The study was conducted in cytopathology section of Department Of Pathology of our centre. Patients who visited the OPD of our hospital, with complaints of superficial cervical lymphadenopathy were sent for FNAC for pursuing a proper diagnosis. Informed consent was taken from the patients before the procedure. FNAC was performed using 22-23 gauge needle attached to $20 \mathrm{ml}$ syringe. In each procedure, an average of 2 to 3 passes were usually made in the lesion and the aspirated material was smeared into 2-3 slides. Slides were then stained with May Grunwald Giemsa (MGG) stain and using dibutyl phathalate xylene (D.P.X) mountant, prepared for cytological examination by experienced cytologists. The data from the years 2010-2016 (6 years) were retrieved, compiled, summarized and statistically analyzed by frequency distribution and percentage proportion.

\section{Results}

In this 6 years study a total of 1338 patients with cervical lymphadenopathy were examined. In our study, the most common cause of cervical lymphadenopathy was tubercular $(53.8 \%)$, followed by reactive $(27.8 \%)$, metastatic deposits of squamous cell carcinoma (10.6\%), metastatic deposits of adenocarcinoma $(3.8 \%)$ and lastly lymphoma (3.5\%). Following table and figures show the year wise number of cases presented with cervical lymphadenopathy, spectrum of its causes with reference to age groups. (Table No. 1 and Fig No. 1, 2 and 3 ).

Table No. 1.Year Wise Distribution of Cervical Lymphadenopathy

\begin{tabular}{|c|c|c|}
\hline Year & Total No. Of Cases & Percentage (\%) \\
\hline 2010 & 190 & 14.2 \\
\hline 2011 & 160 & 11.9 \\
\hline 2012 & 230 & 17.1 \\
\hline 2013 & 243 & 18.1 \\
\hline 2014 & 248 & 18.5 \\
\hline 2015 & 267 & 19.9 \\
\hline
\end{tabular}


Fig No.1.Age group Wise Distribution of Cervical Lymphadenopathy

\section{AGE GROUP WISE DISTRIBUTION OF PATIENTS}

0-15 years $\quad 16-45$ years $\square>45$ years

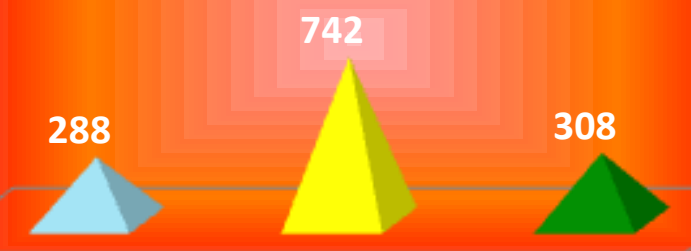

$0-15$ years $\quad 16-45$ years $>45$ years

Fig. No. 2. Spectrum Of Various Diagnosis In Cervical Lymphadenopathy

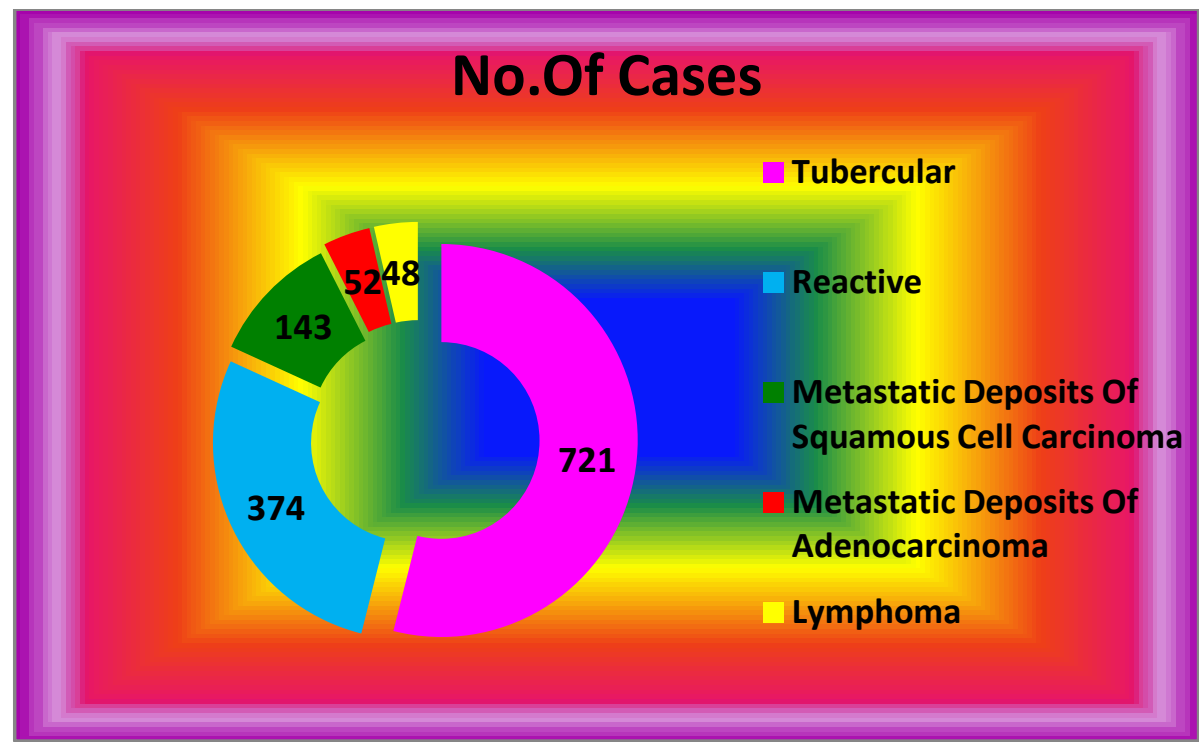

Fig No. 3 Male Vs Female Ratio

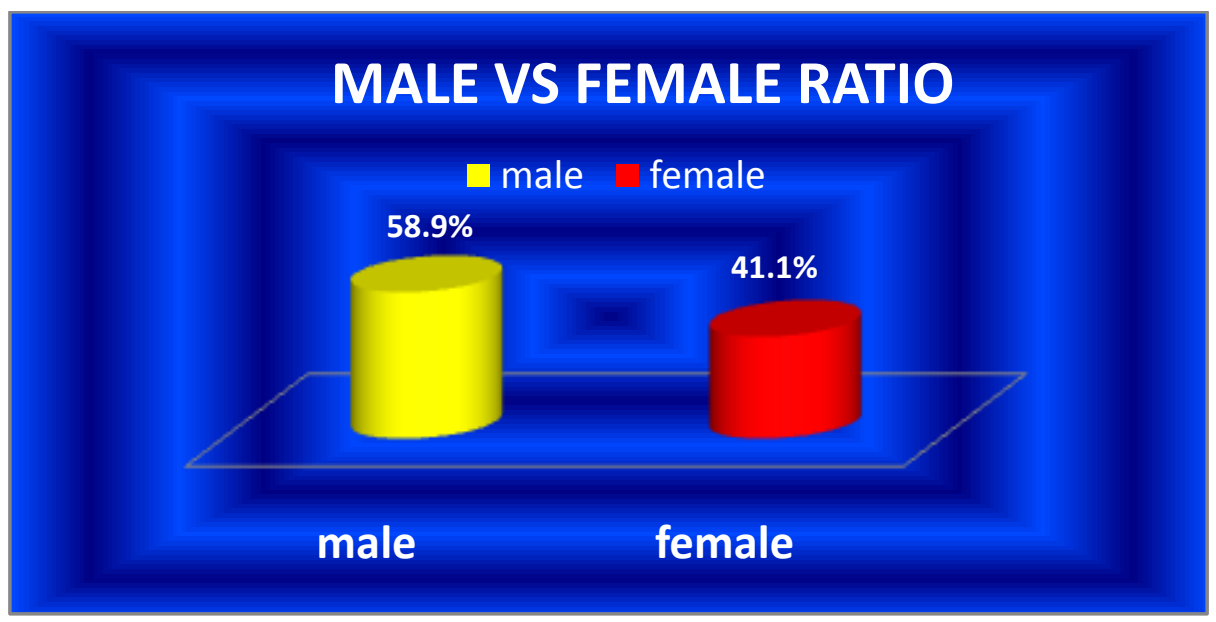


Figure No. 4 Showing Reactive Lymphadenopathy MGG Stain 10X

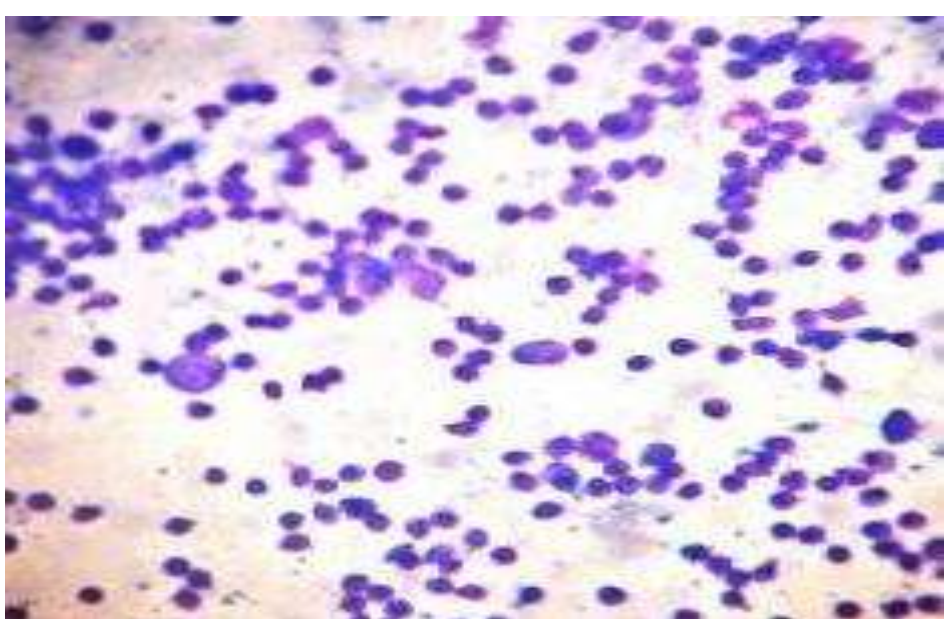

Figure No. 5 Showing Granuloma Formation MGG Stain 10X

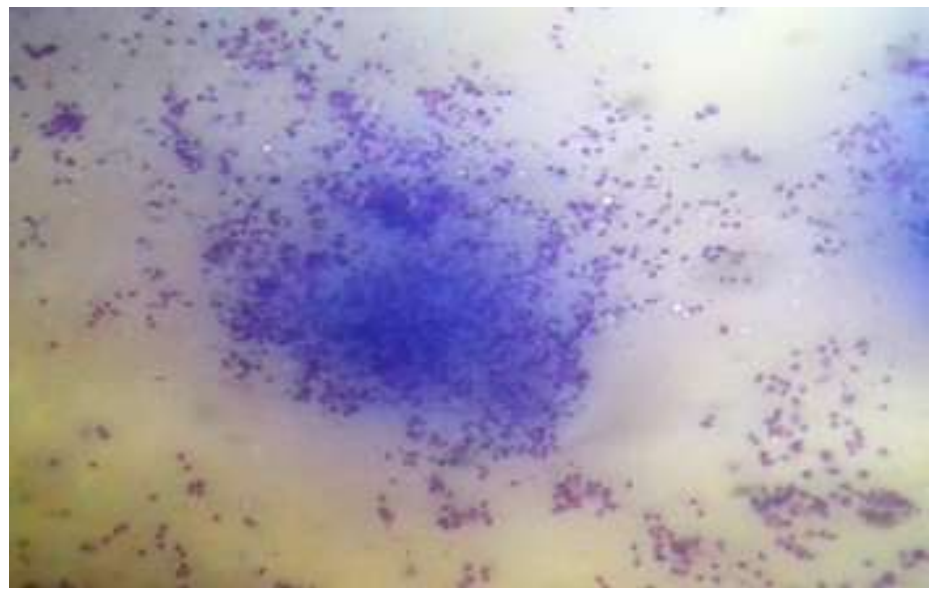

Figure No.6 Showing Metastatic Deposits Of Squamous Cell Carcinoma MGG Stain 40x

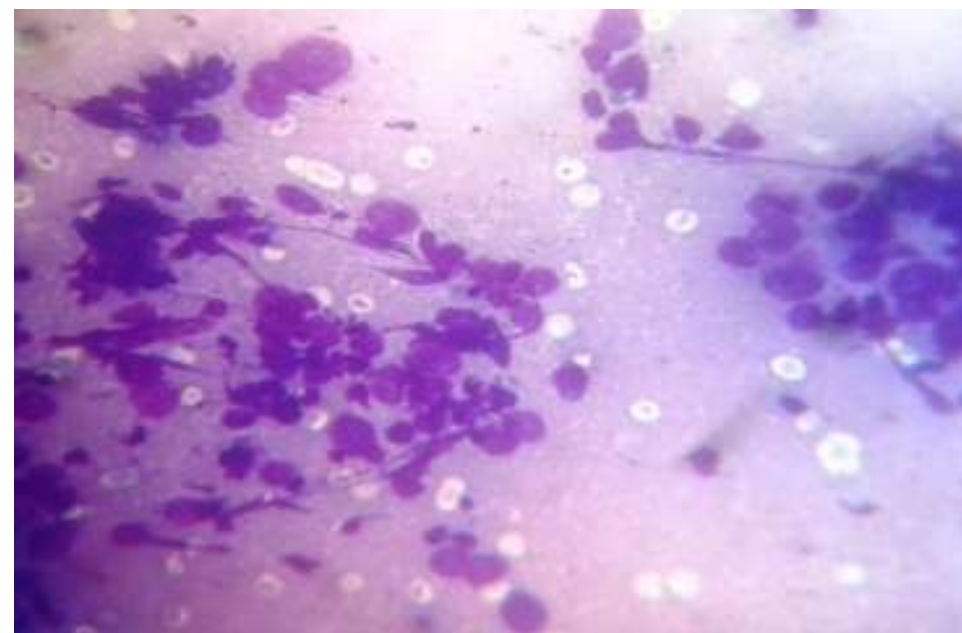




\section{Figure No. 7 Showing Non-Hodgkin's Lymphoma MGG Stain 10X}

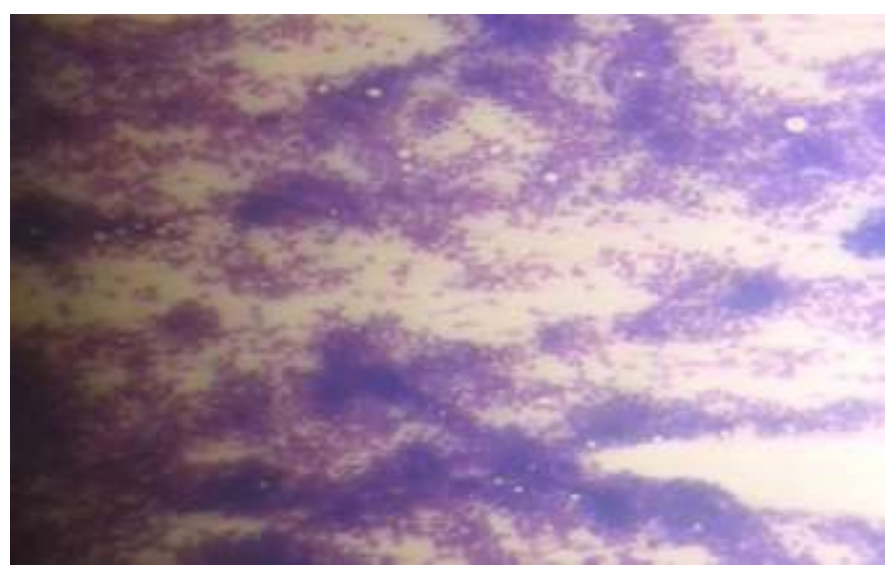

\section{Discussion}

Lymph nodes react to a variety of microorganisms and non-specific stimuli by expansion of the follicle centres and / or interfollicular tissue. This results in the enlargement of nodes which may be considerable. The clinical management of patients with enlarged lymph nodes varies with factors such as age, the presence of known infection and previous medical history. Aspirate from normal lymph nodes shows presence of mature lymphocytes B or T phenotype, plasma cells, centrocytes, centroblasts, immunoblasts and macrophages. Lymphadenopathy is a clinical manifestation of regional or systemic disease which serves as an excellent clue to the underlying disease (Bhuyan et al., 2008) [10]. It can arise either from benign or malignant causes depending upon the geographical condition and socioeconomic set up (Ahmad et al., 2005)[11]. In this study, a total number of 1338 cases of cervical lymphadenopathy were studied out of which $81.8 \%$ were benign and $18.2 \%$ were malignant. Ahmad et al., 2005[11], showed benign causes contributed to $86.4 \%$ of lymphadenopathies. Studies from other developing countries like Pakistan (Khan et al., 2011; Fatima et al., 2011) [12,13] also reported $92 \%$ and $73.2 \%$ benign Lymphadenopathies. In one study from Nepal, benign lesions were reported in $81.5 \%$ cases of lymphadenopathy compared to only $18.5 \%$ of malignant lesions. Nevertheless, this is at variance with report by Steel et al [14] where malignant and benign lesions accounted for 59\% and 34\% respectively.

In our institution, $18.2 \%$ of the lymph node FNAC's yielded malignant diagnoses. Other studies have found the incidence to vary from 5.8[6] to $25.03 \%$.[15,16,17] Our study showed more cases of metastatic involvement of the lymph nodes (14.6\%) rather than lymphomas $(3.6 \%)$. This was similar to other Indian studies $[5,6]$ although there are variations in the percentage involved depending on the number of cases studied. However, an earlier study [18] had documented 102 cases (68\%) of metastases and 42 cases (32\%) involved by lymphomas among 150 cases of malignancies diagnosed by lymph node FNAC. A Brazilian FNAC study on lymph nodes diagnosed $79.4 \%$ metastases and $14.2 \%$ lymphomas [19]. A study conducted in Baghdad has reported more involvement by lymphomas $(58.2 \%)$ rather than metastatic disease $(37.3 \%)$ and $4.4 \%$ involved by leukemia.[20] The diagnostic accuracy of FNAC in metastatic disease varies from $87 \%$ to $97.9 \%[5,6]$ and for lymphomas is $82 \%$.[5] The sensitivity of FNAC for metastatic lesions to lymph nodes has varied from $97.9 \%$ to $100 \%$, whereas the specificity has been found to be $100 \%$.[5,15]

The cervical group is the most common group of lymph nodes to be involved and the primary is most often from the oral cavity[15,21] with squamous cell carcinoma being the most common histological type.[4,5,21].

In our study, the most common cause of cervical lymphadenopathy was tubercular (53.8\%), followed by reactive $(27.8 \%)$, metastatic deposits of squamous cell carcinoma (10.7\%), metastatic deposits of adenocarcinoma (3.9\%) and lastly lymphoma (3.6\%). Similar findings were reported in two studies conducted previously at our institiute by Rajesh Gaur et al [22] and Jyoti Priyadarshini et al [23].

FNA was introduced in most medical centers with a view to reduce the number of excisional biopsies of lymph nodes. Although, a routine procedure, surgical excision is considerably more expensive and time consuming, and is afflicted with a higher morbidity than FNA. Using cytomorphology alone it is often possible to decide if the lymphadenopathy has resulted from reactive lymphadenitis, infection, metastatic malignancy or lymphoma.

\section{Conclusion}

Fine needle aspiration cytology is an effective and reliable tool in the diagnosis of superficial cervical lymphadenopathy. This may be recommended as the first line of investigation in the diagnosis of any palpable clinically suspicious lymph node enlargement for patients who may not be able to afford the health cost of 
surgery and biopsy in our locality. It also serves a very helpful tool in management and definitive diagnosis of patients presenting with cervical lymphadenopathy alone with non-contributory clinical and radiological findings. Again, Fine needle aspiration cytology has been proven to be a cost-effective, easy outpatient procedure with relatively economical advantages, than various expensive and much more invasive procedures which are time consuming and irreconcilable to the patients.

\section{References}

[1]. Guthrie CG. Gland puncture as a diagnostic measure. Bull Jhons Hopkins Hosp 1921;32:266-69.

[2]. Celeste NP. (1996).Williams JF. Fine needle aspiration biopsy of the head and neck. USA: Butterworth Heinemann;.p 1-13.

[3]. Layfield LJ. (1996). Fine-needle aspiration of the head and neck. Pathology (Phila) 4:409-38.

[4]. Bagwan IN, Kane SV, Chinoy RF. Cytologic evaluaton of the enlarged neck node: FNAC utility in metastatic neck disease. Int J Pathol. 2007;6:2.

[5]. Alam K, Khan A, Siddiqui F, Jain A, Haider N, Maheshwari V. Fine needle aspiration cytology (FNAC): A handy tool for metastatic lymphadenopathy. Int J Pathol. 2010;10:2.

[6]. Khajuria R, Goswami KC, Singh K, Dubey VK. Pattern of lymphadenopathy on fine needle aspiration cytology in Jammu. JK Sci. 2006;8:157-9.

[7]. Singh K, Dubey VK, KhajuriaR.Diagnostic accuracy of fine needle aspiration cytology when compared to histopathology. J Cytol 2003; 20: 22-7.

[8]. Martin DA, Janes OA, Allen SL, John nd EN. Clinical Oncology 2 Ed. London (UK): Churchill Livingstone Inc. 2000:2620-9.

[9]. Martin SE,Zhang HZ, Magyarosy E, et al. Immunologic Methods in cytology: definitive diagnosis of non-hodgkin's lymphoma using immunological markers for T and B cells. AM J Clin pathol 1984; 80:666-73.

[10]. Bhuyan MAH, Fakir MAY, Hossain ABMT, Huq AHMZ, Gupta S (2008).Role of Fine needle aspiration cytology in the diagnosis of cervical lymphadenopathy. Bangladesh J Otorhinolaryngol, 14, 63-5.

[11]. Ahmad SS, Akhtar S, Akhtar K, Naseem S, Mansoor T (2005). Study of fine needle aspiration cytology in lymphadenopathy with special reference to Acid-fast staining in cases of tuberculosis. JK Science, 7, 1-4.

[12]. Khan AH, Hayat AS, Baloch GH, et al (2011). Study on the role of fine needle aspiration cytology in cervical lymphadenopathy. World Applied Sci J,12, 1951-4.

[13]. Fatima S, Arshad S, Ahmed Z, Hasan SH (2011). Spectrum of Cytological Findings in Patients with Neck LymphadenopathyExperience in a Tertiary Care Hospital in Pakistan. Asian Pac J Cancer Prev, 12,1873-5.

[14]. Steel BL, Schwartz MR, Ibrahim R (1995).Fine needle aspiration biopsy in diagnosis of lymphadenopathy in 1,103 patients. Acta Cytolo, 39, 76-81.

[15]. Hirachand S, Lakhey M, Akhter P, Thapa B. Evaluation of fine needle aspiration cytology of lymph nodes in Kathmandu Medical College, Teaching hospital. Kathmandu Univ Med J. 2009;7:139-42. [PubMed]

[16]. Ahmad T, Naeem M, Ahmad S, Samad A, Nasir A. Fine needle aspiration cytology (FNAC) and neck swellings in the surgical outpatient. JAMC. 2008;20:30-2. [PubMed]

[17]. Paul PC, Goswami BK, Chakraborti S, Giri A, Pramanik R. Fine needle aspiration cytology of lymph nodes: An Institutional study of 1448 cases over a five year period. J Cytol. 2004;21:187-90.

[18]. Arora B, Beena KR, Arora DR. Utility of fine needle aspiration cytology in lymphadenopathies. J Cytol.1999;16:61-6.

[19]. Martins MR, Santos GC. Fine-needle aspiration cytology in the diagnosis of superficial lymphadenopathy: A 5-year Brazilian experience. Diagn Cytopathol. 2006;34:130-4. [PubMed]

[20]. AlAlwan NA, AlHashmi AS, Salman MA, AlAttar EA. Fine needle aspiration cytology versus histopathology in diagnosing lymph node lesions. East Mediterr Health J. 1996;2:320-5.

[21]. Hoft S, Muhle C, Brenner W, Sprenger E, Maune S. Fine-needle aspiration cytology of the sentinel lymph node in head and neck cancer. J Nucl Med. 2002;43:1585-90.

[22]. Dr Rajesh Gaur, Dr Poonam Woike Spectrum Of Cytological Findings In Patients With Superficial Lymphadenopathy: A Five Year Retrospective Study Jmscr Vol||3||Issue||10||Page7933-7939||OctoberDoi:Http://Dx.Doi.Org/10.18535/Jmscr/V3i10.37.

[23]. Jyoti Priyadarshini Shrivastava1, Alok Shrivastava 2, Sandeep Singh3, Rajesh Gaur4 ROLE OF FNAC IN THE EVALUATION OF CERVICAL LYMPH NODES: A HOSPITAL BASED STUDY. July Volume :4 Issue :55 Page :9643-9644.

Author's contribution- This work was carried out in collaboration between all authors. Author Poonam Woike designed the study, wrote the protocol, managed the literature searches, analysis of the study performed and wrote the first draft of the manuscript. Author Ravi Bhagat managed the experimental process. Authors Rajesh Gaur and Dharmesh Chandra Sharma supervised the research work. All authors read and approved the final manuscript. 